\section{Transparencia en la gestión pública y privada del Perú frente a la crisis de valores que afectan el desarrollo del país}

\author{
Transparency in public and private management of Peru in \\ the face of the crisis of values that affect the development of \\ the country
}

\begin{abstract}
RESUMEN
El Perú al igual que muchos países latinoamericanos viene atravesando una de las más severas crisis de corrupción en su historia que comprende a autoridades elegidas, funcionarios de todos los niveles de la administración pública (poderes del estado: ejecutivo, legislativo y judicial, así como a los gobiernos regionales y locales) y ejecutivos de empresas privadas del sector construcción. Dicha situación ha originado, origina y originará impactos muy severos en el desarrollo político, económico y social del país. En materia política se incrementa el factor riesgo país, desacelerando y desalentando las inversiones extranjeras y nacionales, motor de la economía del país.

En materia económica, la involución del factor más importante de la macro economía, como es el PBI (Producto Bruto Interno) y a pesar que la actual coyuntura económica la ha estabilizado en el ejercicio 2018, cerrando con $3.8 \%$, continua con visos de no evolucionar por los problemas coyunturales y estructurales del país en todos sus sectores productivos y de servicios. En materia social, el fenómeno del niño costero, el decrecimiento de la población económicamente activa (PEA), y la migración extranjera, que en su gran mayoría no es mano de obra calificada, han incrementado las poblaciones vulnerables (pobreza y extrema pobreza).

Este resumen apretado, que refleja una profunda preocupación, se ha visto incrementada exponencialmente con la corrupción en todos los sectores y niveles de la estructura política, económica y social del país, lo que ocasiona la pérdida de confianza en la clase política. Situación que me motivó a preparar el presente artículo de reflexión, en la seguridad de una sociedad con valores, con educación de calidad o cero tolerancias a la inseguridad ciudadana son la única forma de garantizar su desarrollo sostenido del país en el tiempo.

Palabras claves: Transparencia; Gestión Pública; Gestión Privada; Valores y Desarrollo político; económico y social del país.
\end{abstract}

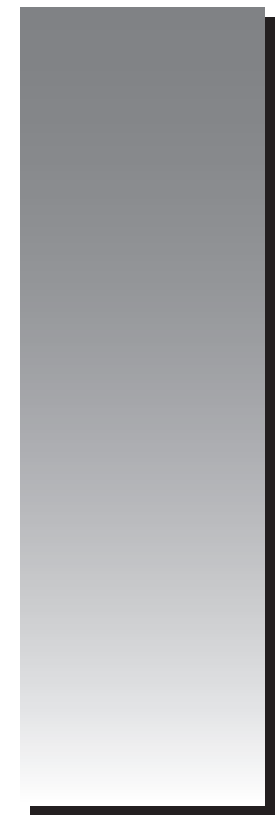

Luis Fernando Valeriano Ortiz

lfernandovaleriano@yahoo.es

Universidad Nacional Mayor de San Marcos, Facultad de Ciencias Administrativas. Lima, Perú 


\begin{abstract}
Peru, like many Latin American countries, has been going through one of the most severe corruption crises in its history that includes elected officials, officials of all levels of public administration (powers of the state: executive, legislative and judicial, as well as regional and local governments) and executives of private companies in the construction sector. This situation has originated, originates and will cause very severe impacts on the political, economic and social development of the country.

In political matters, the country risk factor is increased, slowing down and discouraging foreign and domestic investments, the engine of the country's economy.

In economic terms, the involution of the most important factor of the macro economy, such as the GDP (Gross Domestic Product) and despite the current economic situation has stabilized in the year 2018, closing with $3.8 \%$, continues with signs of not evolving due to the country's structural and structural problems in all its productive and service sectors.

In social matters, the phenomenon of the coastal child, the decrease of the economically active population (EAP), and foreign migration, which in its great majority is not skilled labor, have increased vulnerable populations (poverty and extreme poverty).

This tight summary, which reflects a deep concern, has been exponentially increased with corruption in all sectors and levels of the political, economic and social structure of the country, which causes the loss of confidence in the political class. Situation that motivated me to prepare this article of reflection, in the security of a society with values, with quality education or zero tolerance for citizen insecurity are the only way to guarantee the sustained development of the country over time.
\end{abstract}

Keywords: Transparency Public management; Private Management; Values and Political Development; economic and social of the country.

\section{INTRODUCCIÓN}

El mundo globalizado, la participación del Perú en los organismos multinacionales y la firma de tratados de libre comercio con países como USA, Comunidad Europea y países asiáticos son factores del entorno que fortalecen la economía del Perú. La estabilidad política, las inversiones nacionales y extranjeras, el desarrollo de programas de inclusión y de responsabilidad social son factores del entorno que reactivan el desarrollo del país. Sin embargo, las tareas pendientes son apostar por una educación de calidad en todos los niveles y contar de un sistema de salud que logre disminuir las tasas de mortalidad y anemia infantil. El sector empresarial debe promover una filosofía de competitividad y por ende de calidad de los productos y servicios que se generen en la industria nacional para satisfacer la demanda de los mercados. Todo este accionar dentro de la transparencia en la gestión pública y privada del Perú como respuesta a la crisis de valores de autoridades y empresarios, que afectan el desarrollo del país.

El éxito de los países asiáticos en las últimas décadas del siglo precedente, que tenían un desarrollo económico y social incipiente, en el presente siglo son líderes en sus economías a nivel mundial y su desarrollo se centra en apostar por una educación de calidad en todos los niveles del sistema educativo, porque promovieron y fortalecieron los programas de investigación y desarrollo a nivel privado y público, destacando la creatividad e innovación de su talento humano (patentes y propiedad intelectual) y porque fueron y son muy rigurosos con la cero tolerancia a la inseguridad ciudadana y la inmoralidad en la gestión pública y privada, se combate y aplica sanciones drásticas a sus infractores, sean corruptos o corruptores, no pudiéndose convivir con la inmoralidad. 
En esta era de la gestión del conocimiento, que promueve la investigación y el desarrollo en los países, se alienta la creatividad e innovación en las personas, los países con crecimiento sostenido de sus economías apuestan por un crecimiento anual del 6 u $8 \%$ de su PBI, destinan recursos económicos para el PBI Educativo con el $6 \%$, de igual forma $2 \%$ a $3 \%$ del PBI para investigación y desarrollo y las empresas privadas asignan no menos del $10 \%$ de sus ventas reflejadas en sus estados financieros para la investigación, en consecuencia se hace necesario que las entidades de la administración pública y las privadas del país contribuyan al desarrollo el Perú con investigaciones básicas o aplicadas en ciencia, tecnología y humanidades de calidad orientadas al crecimiento del país sobre la base de la transparencia en su gestión con valores, moral, ética y deontología profesional.

Corresponde al Estado a través de los Gobiernos de turno fortalecer el núcleo familiar de los peruanos, que es la célula básica de la sociedad, mediante programas de desarrollo social integrados a los sectores productivos, sociales y económicos, dentro de una cultura de valores, moral y ética en su comportamiento como seres comprometidos con el cambio social, para mitigar la extrema pobreza, el analfabetismo, la anemia infantil y otros flagelos que atentan con la calidad de vida de los peruanos.

De igual forma, se requiere una reingeniería total del sistema educativo del país, que comprende todos sus niveles educativos: inicial, básica, instituciones tecnológicas y universitaria públicas y privadas, que promuevan no solo una calidad en la formación educativa profesional, según sea el caso, sino también formar personas con sentido crítico y constructivo, con identidad nacional y fundamentalmente con valores.

En la gestión pública debe eliminar los cargos de confianza, las autoridades elegidas en procesos electorales deben acreditar no contar con antecedentes penales, judiciales y policiales y por delitos de terrorismo, los funcionarios públicos deben ser reclutados y seleccionados mediante la meritocracia, que respondan al perfil del puesto de trabajo y a las competencias laborales. Se debe aprobar una nueva ley laboral para la administración pública y actividad privada, los procesos administrativos iniciados a los trabajadores se deben respetar, el debido proceso y el derecho a la defensa del investigado y que las medidas disciplinarias impuestas por inconductas funcionales sean registradas a nivel del sector público nacional, y en caso de gravedad que linde con el delito cometido este sea ventilado en la vía judicial en el fuero que corresponda.

La empresa privada que participa como proveedores de productos y servicios en la administración pública debe estar en el registro de proveedores y su participación concursal está condicionada a no contar con sanciones en las modalidades de compras en la que ha participado.

La Facultad de Ciencias Administrativas de la Universidad Nacional Mayor de San Marcos debe asumir el compromiso de promover el desarrollo de proyectos de transparencia en la gestión pública y la actividad privada, mediante capacitaciones, seminarios, eventos nacionales e internacionales, etc. en la que participen sus autoridades, docentes, estudiantes, egresados y de ser el caso invitar a profesionales de reconocido prestigio y solvencia moral a nivel nacional e internacional, para contribuir al fortalecimiento de la solvencia y reserva moral a nivel país.

\section{OBJETIVO DEL ENSAYO}

Contribuir mediante este artículo de reflexión, a promover la creación de círculos de valores en cada entidad del sector público y de la actividad privada del país, para optimizar la transparencia en la gestión y mejorar el desarrollo del país, mediante una cultura de valores, ética y moral a lo largo del ciclo de vida del ser humano.

\section{ARGUMENTACIÓN}

\section{Marco legal.}

La Constitución Política del Perú se promulgo en 1993, han transcurrido más de 25 años de su vigencia, requiere ser actualizada y no modificada, es demasiada reglamentaria para algunos sectores e imprecisa para las sanciones administrativas que imponen los organismos públicos a los funcionarios por las inconductas funcionales cometidas y acreditadas, de igual forma el rol de los Procuradores que defienden los intereses del Estado ante el Poder Judicial y el Ministerio Pu- 
blico que defiende las intereses de la sociedad no cuentan con los recursos necesarios para el cumplimiento de su función y la Contraloría General de la Republica tienen un papel poco relevante reflejadas en los resultados de las auditorias en la vía administrativa. En definitiva, la transparencia en la gestión pública debe ser materia de un capítulo aparte y muy precisa, para que tenga fuerza constitucional.

\section{Marco político.}

La crisis política que vive el país en estas últimas décadas, acentuada por el soborno de las empresas constructoras brasileras a las más altas autoridades del país en los diferentes gobiernos, ponen en evidencia la falta de vocación de servicio de quienes asumen roles de gobernabilidad nacional, regional, local, parlamentaria, judicial, policial etc., quienes lograron llegar al poder solo para enriquecerse ilícitamente, rindiendo culto al dinero mal habido, sin importarles que en el Perú, el $30 \%$ de su población está en situación vulnerable, significa pobreza y extrema pobreza, esta situación ha causado un grave daño a la sociedad peruana y que le demandara mucho años para corregirla, pero estamos seguros que nuestro país es más grandes que nuestros propios problemas.

Los partidos políticos requieren de una reingeniería total, modernización de su doctrina partidaria, actualización de sus padrones, dando oportunidad a nuevos cuadros dirigenciales que emanen del voto popular partidario y no apostar por la relección por ningún cargo elegido partidariamente.

El Poder Judicial, el Ministerio Publico, los Procuradores Generales de la República y los organismos de control y de fiscalización como es el Sistema Nacional de Control, requieren de una restructuración total para garantizar transparencia, legalidad y objetividad en sus decisiones de su competencia sobre la base del respeto del debido proceso y el derecho a la defensa de las personas, despolitizándolas de todo compromiso partidario.

De igual forma los medios de comunicación social, escrita, televisada, redes sociales, etc. deben informar no en función a los intereses de sus dueños, sino de la sociedad y de la objetividad de los hechos, no confundiendo la libertad de prensa con libertinaje, sus programas y contenidos deben difundir programas educativos, recreativos, respetar la cultura y los valores de los pueblos.

\section{Marco económico}

He tomado como referencia el Informe del Banco Interamericano de Desarrollo - Gobiernos de América Latina y El Caribe, en la que se precisan similitudes a los problemas económicas del Perú. Los escritores del periódico digital El País, Linde y Fariza (2018) mencionan:

Cada año, la ineficiencia en el gasto de los Gobiernos de América Latina y el Caribe genera un despilfarro total de 220.000 millones de dólares, el equivalente a un 4,4\% del PIB. "Esa cifra, bien invertida, sería suficiente para acabar con la pobreza extrema en la región", asegura Alejandro Izquierdo, economista jefe del Banco Interamericano de Desarrollo (BID). El Banco Interamericano de Desarrollo identifica tres grandes fuentes de ineficiencia presentes, en mayor o menor grado, en todos los países de Latinoamérica y el Caribe: compras públicas por problemas en las licitaciones, ineficiencias en selección de proyectos de inversión adecuados o corrupción, elevando la eficiencia se podría ahorrar el equivalente 1,5\% del PIB de la región-, transferencias monetarias a los ciudadanos -muchas veces los receptores no son los que más las necesitan, con lo que se fomenta la desigualdad y se despilfarra aproximadamente el 1,7\% del PIB-y los salarios públicos -los sueldos de los funcionarios representan un porcentaje mayor del presupuesto público total en América Latina y el Caribe (29\%) (Ver Figura 1).

Según el Instituto Nacional de Estadística e Informática, el Informe Económico del Perú se muestra en los siguientes gráficos:

La Figura 2 muestra la caída del crecimiento hacia un porcentaje algo menor de $4 \%$ del PBI periodo 2018. Un ritmo de crecimiento insuficiente para la reducción de la pobreza y la absorción de la demanda de empleo.

Como consecuencia de la caída del crecimiento del PBI, podemos ver cómo, después de tres lustros, vuelve a crecer la pobreza en el 2017.

Es consecuencia directa de la menor inversión, tanto la pública como privada y el alto grado de corrupción de los diferentes gobiernos. 
Transparencia en la gestión pública y privada del Perú frente a la crisis de valores que afectan el desarrollo del país

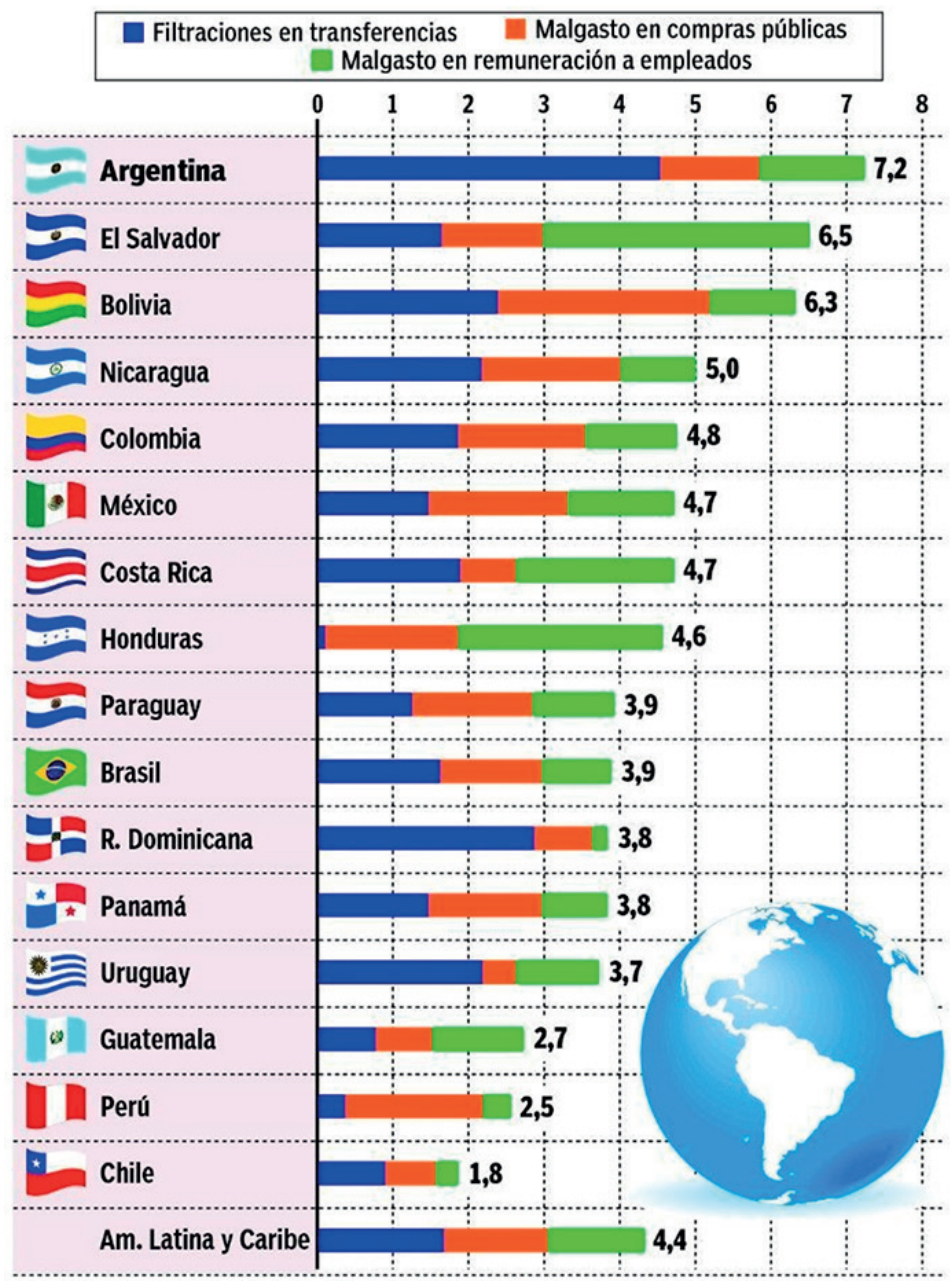

Figura 1. Estimación de la ineficiencia técnica: transferencias focalizadas, compras públicas y remuneración a empleados en porcentajes de PBI, país con país. Fuente: El Banco Internacional de Desarrollo.

\section{Tasa de crecimiento del PBI real, 1993-2019* (Variación \% anual)}

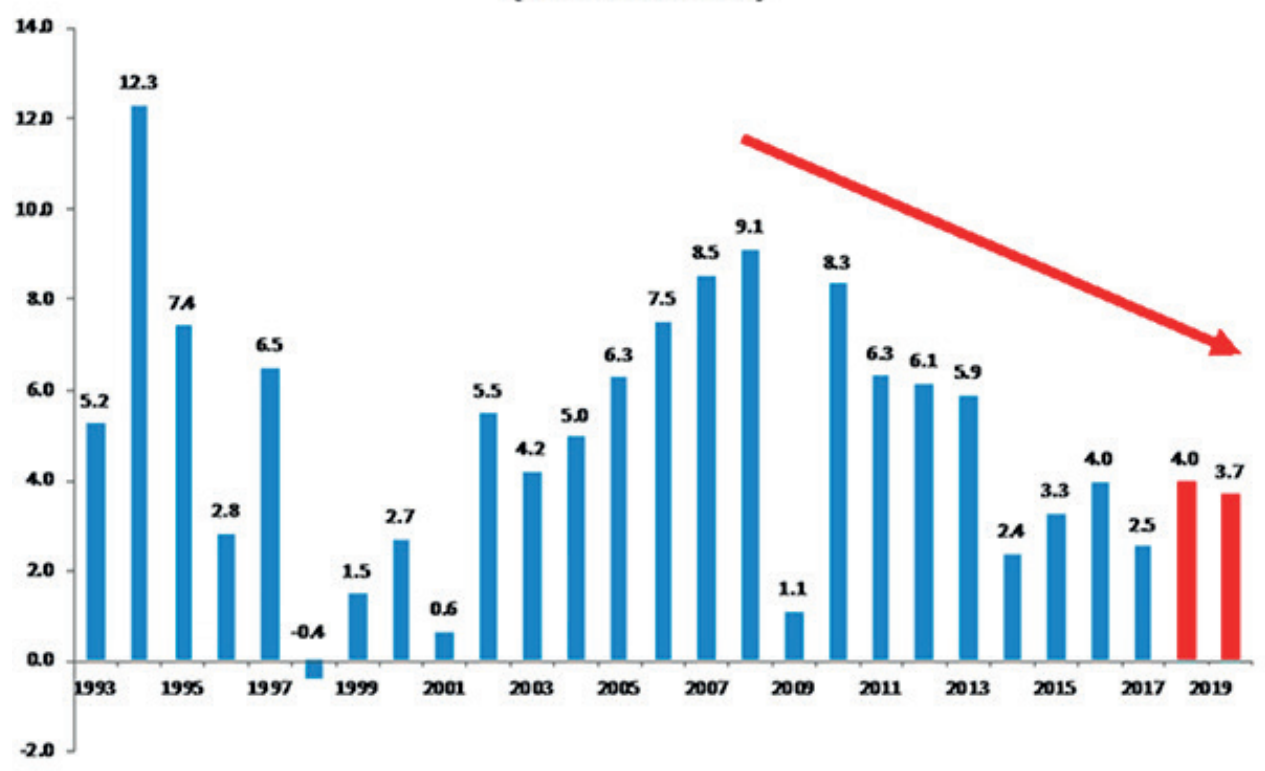

Figura 2. Tasa de crecimiento del PBI real, 1993-2019. Elaborado por Lampadia. Fuente: Instituto Nacional de Estadística e Informática. 


\section{Pobreza y pobreza extrema, 2004-2018}

(\% de la población peruana)

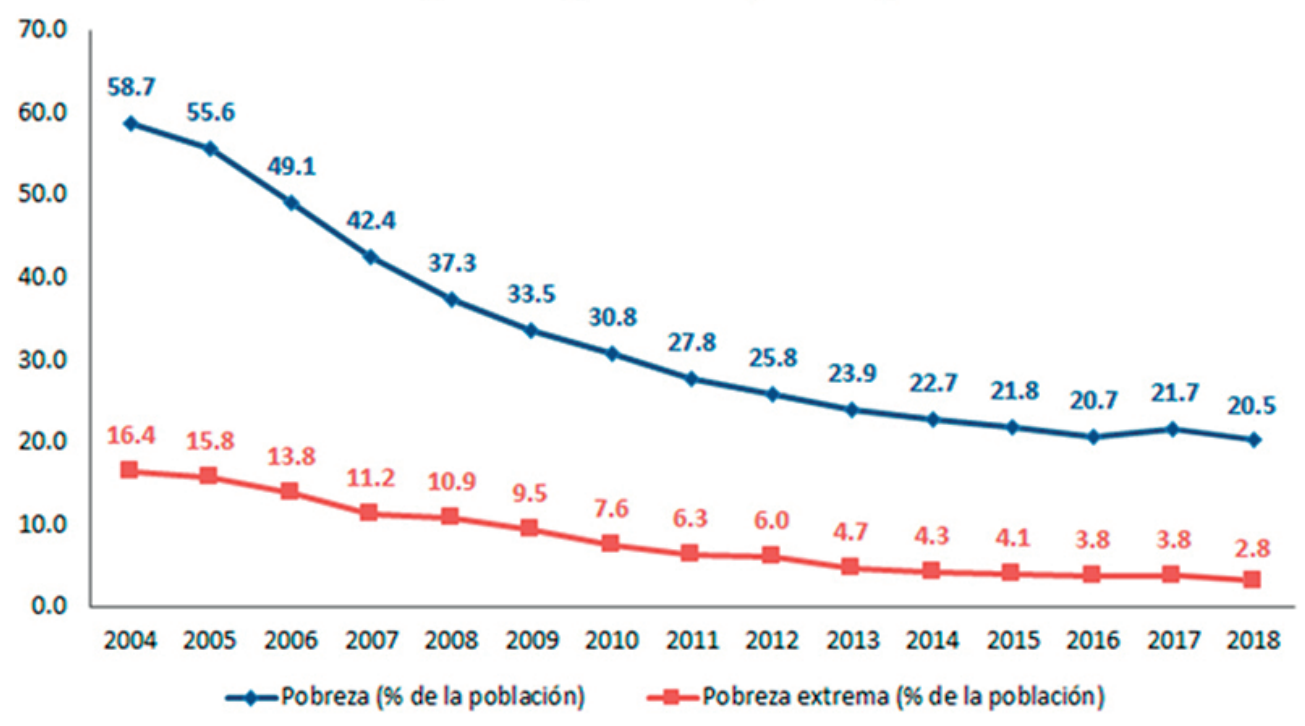

Figura 3. Pobreza y pobreza extrema, 2004-2018. Elaborado por Lampadia.

Fuente: Instituto Nacional de Estadística e Informática.

\begin{tabular}{|c|c|c|c|c|c|c|}
\hline & \multicolumn{2}{|c|}{2013} & \multirow{2}{*}{$\begin{array}{c}2017 \\
\begin{array}{c}\text { En millones de } \\
\text { uss }\end{array}\end{array}$} & \multirow{2}{*}{$\begin{array}{c}2018^{*} \\
\text { En millones de } \\
\text { uss }\end{array}$} & \multirow{2}{*}{\begin{tabular}{|c|}
$2018^{*}$ \\
Como $\$$ del PBI \\
2013
\end{tabular}} & \multirow{2}{*}{$\begin{array}{l}\text { Brecha de } \\
\text { Inversión } \\
\text { Real }\end{array}$} \\
\hline & $\begin{array}{l}\text { En millones de } \\
\text { uss }\end{array}$ & $\mathbf{X}$ del $\mathrm{PBa}$ & & & & \\
\hline Inversión Total & 54,577 & $26.9 \%$ & 45,089 & 47,711 & 60,067 & 12,357 \\
\hline Inversión Privada & 42,810 & $21.1 \%$ & 35,427 & 37,092 & 47,116 & 10,024 \\
\hline Inversión Privada Nadional & 33,512 & $16.5 \%$ & 29,420 & 30,828 & 36,883 & 6,054 \\
\hline Inversión Privada Extranjera & 9,298 & $4.6 \%$ & 6,007 & 6,264 & 10,233 & 3,969 \\
\hline Inversión Pública & 11,768 & $5.8 \%$ & 9,662 & 10,618 & 12,951 & 2,333 \\
\hline PBI & 202,889 & $100.0 \%$ & 214,710 & 223,298 & 223,298 & \\
\hline
\end{tabular}

Figura 4. La caída de la inversión, 2013-2018.

Elaborado por Lampadia. Fuente: Banco Central de Reserva del Perú y Proinversión.

La figura 4 muestra cómo ha caído la inversión desde el año 2013. Pasamos de invertir hasta US $\$ 55,000$ millones anuales a US $\$ 45,000$ millones el 2017 y un estimado de US\$ 48,000 millones el 2018. Pero si tomamos como base el porcentaje de inversión sobre el PBI del 2013 de $26.9 \%$, y lo proyectamos al 2018 tenemos una brecha de menor inversión, con respecto al 2013, de US\$12,000 millones anuales. US\$ 10,000 millones menos de inversión privada y US\$2,000 menos de inversión pública.

La perspectiva hacia adelante es más de lo mismo, un crecimiento mediocre y muy por debajo de lo que el Perú puede lograr. Veamos las estimaciones del BCRP en la figura 5.
En la figura 6 podemos apreciar que el motor que nos dio un gran crecimiento hace algunos años, el sector minero, está prácticamente parado. La minería cayó un 1.1\% el 2018, el Banco Central proyecta un crecimiento de $5.1 \%$ para el año actual y un pobrísimo crecimiento de $2.5 \%$ para el 2020 . Producto exclusivamente de la debilidad y la corrupción de los gobiernos para impulsar la inversión minera y la diversificación productiva de sectores como la agro exportación y el textil y el sector turismo.

El Perú es un destino privilegiado para las inversiones mineras. Inversiones que toman tiempo en concretarse y que, al perderlas, nos 


\begin{tabular}{|c|c|c|c|c|}
\hline \multirow[t]{3}{*}{ BCRP } & \multicolumn{4}{|c|}{$\begin{array}{c}\text { DEMANDA INTERNA Y PBI } \\
\text { (Variaciones porcentuales reales) }\end{array}$} \\
\hline & \multirow{2}{*}{2017} & \multirow{2}{*}{2018} & \multicolumn{2}{|c|}{ RI. Mar. 2019} \\
\hline & & & $2019^{*}$ & $2020^{*}$ \\
\hline Demanda interna & 1,4 & 4,3 & 3,9 & 4,1 \\
\hline Consumo privado & 2,6 & 3,8 & 3,8 & 3,9 \\
\hline Consumo público & 0,5 & 2,0 & 2,5 & 2,2 \\
\hline Inversión privada & 0,2 & 4,4 & 6,5 & 6,0 \\
\hline Inversión pública & $-2,3$ & 8,4 & 1,0 & 5,0 \\
\hline Exportaciones & 7,8 & 2,5 & 4,6 & 5,7 \\
\hline Importaciones & 4,1 & 3,4 & 4,4 & 6,2 \\
\hline$\underline{\underline{P B I}}$ & $\underline{2.5}$ & $\underline{4.0}$ & $\underline{4,0}$ & $\underline{4,0}$ \\
\hline \multicolumn{5}{|l|}{ Nota: } \\
\hline Gasto público & $-0,3$ & 3,8 & 2,1 & 3,0 \\
\hline Demanda interna sin inventarios & 1,7 & 3,9 & 4,0 & 4,1 \\
\hline
\end{tabular}

RI: Reporte de Inflación "Proyección

Figura 5. Demanda interna y PBI, 2017-2020. Fuente BCRP.

\begin{tabular}{lllll|} 
BCRP & \multicolumn{3}{l}{$\begin{array}{c}\text { PBI POR SECTORES ECONÓMICOS } \\
\text { (Variaciones porcentuales reales) }\end{array}$} \\
\hline & 2017 & 2018 & \multicolumn{2}{c|}{ RI. Mar.19 } \\
\cline { 4 - 6 } & & & $2019^{*}$ & $2020^{*}$ \\
\hline & & & & \\
\hline PBI primario & 3,1 & 3,3 & 3,0 & 3,4 \\
\hline Agropecuario & 2,6 & 7,5 & 4,5 & 4,0 \\
Pesca & 4,7 & 39,7 & $-4,5$ & 2,0 \\
Mineria e hidrocarburos & 3,4 & $-1,3$ & 3,2 & 3,6 \\
Manufactura primaria & 1,9 & 13,2 & 0,5 & 1,2 \\
& & & & \\
\hline PBI no primario & $\mathbf{2 , 3}$ & $\mathbf{4 , 2}$ & $\mathbf{4 , 2}$ & $\mathbf{4 , 2}$ \\
\hline Manufactura no primaria & $-0,9$ & 3,7 & 4,0 & 3,8 \\
Electricidad y agua & 1,1 & 4,4 & 4,5 & 4,5 \\
Construcción & 2,1 & 5,4 & 6,5 & 7,5 \\
Comercio & 1,0 & 2,6 & 3,4 & 3,5 \\
Servicios & 3,3 & 4,4 & 4,2 & 4,0 \\
& & & & \\
\hline Producto Bruto Interno & $\underline{\mathbf{2 , 5}}$ & $\underline{4,0}$ & $\underline{4,0}$ & $\underline{4,0}$ \\
\hline \hline
\end{tabular}

- Proyección

RI: Reporte de Inflación

Figura 6. PBI por Sectores Económicos, 2017-2020.

Fuente BCRP

pasarán la factura, en forma de estancamiento, más adelante.

Ese estancamiento debe ser contrastado con nuestro potencial de crecimiento, que más allá de los cálculos económicos, apreciando nuestro potencial de crecimiento productivo, es seguramente del orden de 6 a $7 \%$ anual.

El Perú, su gente y sus recursos son bastos como para sustentar, en paralelo a los temas institucionales, un mejor futuro económico y social. 
No podemos seguir perdiendo tantas oportunidades para consolidar el bienestar general.

\section{Marco social.}

El Perú en las últimas viene realizando esfuerzos para disminuir la pobreza y extrema pobreza de sus habitantes, a través de los programas sociales y estabilizando la economía, sin embargo, las cifras son alarmantes, se señala que el 30\% de la población total está en situación vulnerable, que se ve incrementado con la migración de extranjeros que vienen en busca de nuevas oportunidades laborales.

El Instituto Nacional de Estadística e Informática (2018) señala:

Unas 313.000 personas salieron de la pobreza durante el año pasado. Al término del año 2018, el 20.5\% de la población del país --que equivale en cifras absolutas a 6’593.000 personas-- se encontraba en situación de pobreza, es decir tenían un nivel de gasto inferior al costo de la canasta básica de consumo compuesto por alimentos y no alimentos, según el informe Evolución de la Pobreza Monetaria 20072018 dado a conocer por el INEI.

La tasa de pobreza del 2018 reflejó una disminución de 1,2 puntos porcentuales en comparación con el resultado en 2017. Con esto, unas 313.000 personas salieron de la pobreza el año pasado.

El jefe del INEI, explico que para medir la pobreza monetaria se consideró al gasto como indicador de bienestar, el cual fue valorizada para el año 2018 en S/344 por persona, de esta manera para una familia de cuatro miembros el costo de la canasta familiar es de S/1.376. Las personas cuyo gasto per cápita es menor a este monto fueron considerados pobres.

Para medir la pobreza extrema, el funcionario dijo que se valoriza la canasta mínima alimentaria por persona en S/183 y para una familia de cuatro miembros es de S/732. Fueron considerados como pobres extremos cuando el gasto per cápita no cubre el costo de la canasta mínima alimentaria.

De acuerdo con el informe, la pobreza extrema en el Perú se redujo a $2,8 \%$ en
2018 frente al nivel de 3,8\% en 2017. Con esta disminución, unos 309.000 peruanos abandonaron dicha situación de carencia durante el año pasado.

En líneas generales estos porcentajes y cifras no son alentadoras, se requiere mayor profundización para captar mayores inversiones, mejorar el ingreso per cápita de las personas mediante el incremento de la población económicamente activa del país, y tomar medidas drásticas contra los funcionarios que afectan la ejecución de los programas sociales.

\section{Marco educativo.}

El sistema educativo en el Perú en todos sus niveles, reflejan una ausencia e interés por parte de los gobernantes de turno para impulsarlas a niveles de calidad, para lograr la acreditación nacional e internacional. Los presupuestos asignados son diminutos frente a las necesidades de mejora continua, los índices de analfabetismo son alarmantes en el Perú profundo, el problema central está asociado al crecimiento de la economía nacional, mejor distribución de los recursos y a la atención de los problemas sociales y de la salud pública de las poblaciones vulnerables dentro de una concepción integral (Ver figura 7).

Este cuadro refleja el poco interés de los Gobernantes del país por mejorar la calidad de la educación en todos sus niveles, si no se asignan los recursos económicos planteados en el Plan Estratégico del sector educación para un periodo determinado, que comprende la capacitación intensiva de los docentes a nivel nacional en función a la malla curricular, que responda a los avances de la ciencia, tecnología y las humanidades, y que recoja las demandas del magisterio con sueldos decorosos, de que los docentes dominen un idioma extranjero y nativo; así como de asimilar los nuevos programas informáticos orientados a las líneas educativas mediante plataformas tecnológicas implementadas en aulas o laboratorios, de igual forma se comprenda la modernización del material educativo a cargo de docentes y Editoriales Peruanas para garantizar la identidad nacional e inculcarles valores, se implemente infraestructuras educativas estandarizadas para la costa, sierra y selva, de acuerdo con la población educativa a atender, a los alumnos de los centros 


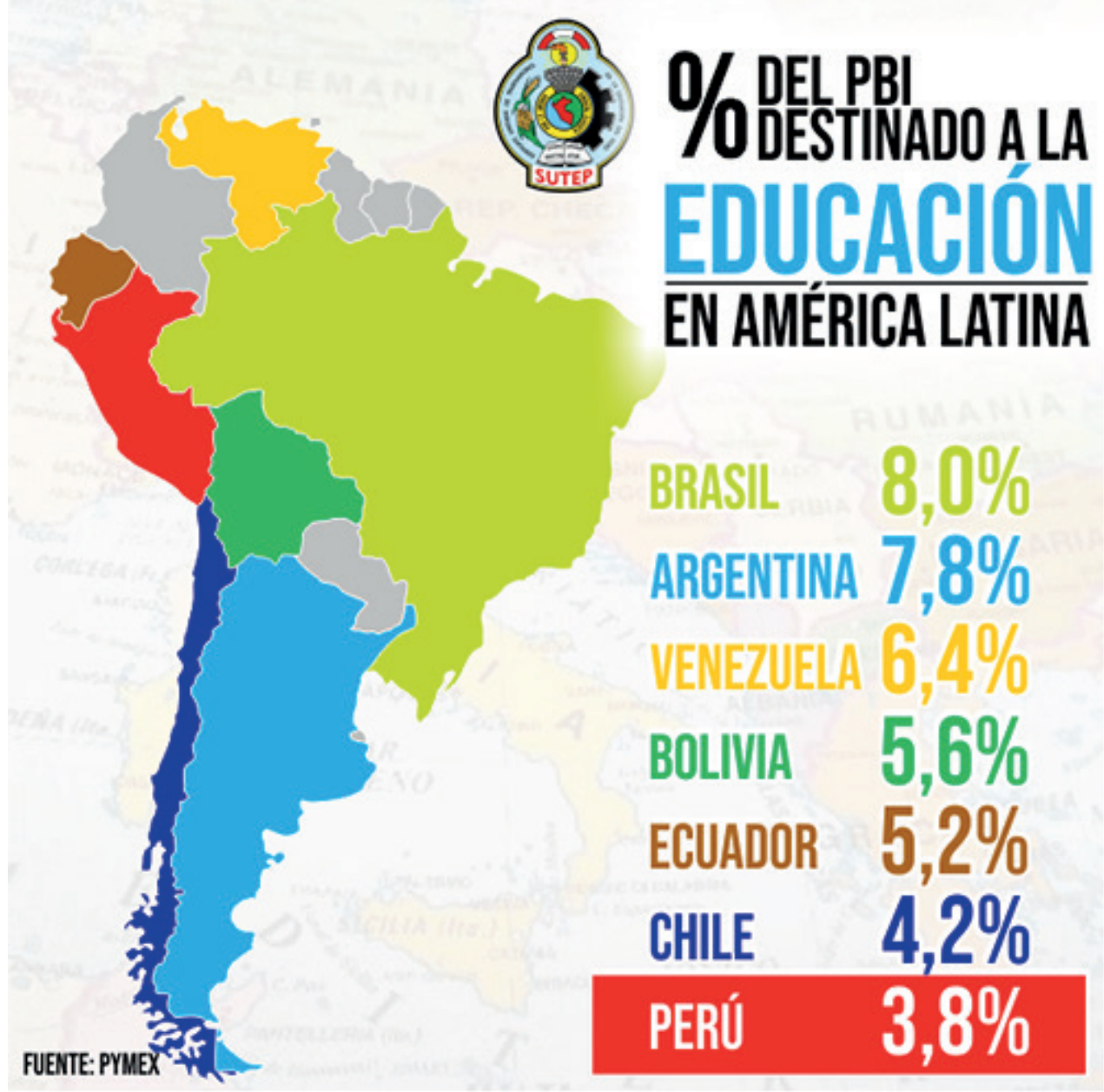

Figura 7. El PBI Educativo en América Latina

Fuente: Pequeña o Mediana Empresa Mexicana (PYMEX)

educativos del estado se le implemente programas de alimentación de calidad, que incluya a sus Docentes, etc. poco o nada se podrá lograr.

Una excelente experiencia es el Colegio Mayor Presidente de la Republica, que funciona en Centro Vacacional de Huampani, que en sus inicios dio una educación de calidad, pero con el tiempo se fue diluyendo por los motivos expuestos, este debió replicarse en todas Regiones del país, para luego implementar un segundo nivel con los Colegios de alto rendimiento a nivel de las provincias. La evaluación Pisa demuestra en la parte cognitiva, que lejos estamos de una educación de calidad.

Problema similar afrontan las Universidades Peruanas, al no acreditar una formación profesional de calidad en casi todas las carreras profesionales de acuerdo a los estándares académicos establecidos para el licenciamiento y la acreditación nacional e internacional. Lo que preocupa es que en las mallas curriculares de las carreras profesionales no están en función a la oferta y demanda del mercado nacional, además no está contemplado las asignaturas de Responsabilidad Social y la de Deontología Profesional, esta última sobre la base de una cultura de valores, ética y moral.

\section{Gestión pública.}

Continúa siendo ineficiente en la prestación de los servicios a la sociedad, sus organizaciones son burocráticas, sus autoridades logran llegar al poder para ganar un sueldo por encima de la actividad privada y se olvidan de la vocación de servicios que es su primer compromiso con el país. La meritocracia en la gestión pública que- 
da en el marco regulatorio, el clientelage político a través de los cargos de confianza y los compromisos políticos partidarios tienen mayor prioridad para asumir cargos en la gestión pública, los programas de capacitación para los trabajadores de la administración pública son mínimos, sus remuneraciones varían de acuerdo a los regímenes laborales público y privado y se mantiene un programa especial CAS, que es una falta de respeto a los derecho de los trabajadores, beneficios diminutos para algunos y para otros sueldos por encimas de las escalas salariales.

El aspecto regulatorio en materia de transparencia en la gestión pública y la aplicación de sanciones disciplinarias por inconductas funcionales, solo se aplican en forma selectiva y no contribuye a la cero tolerancia a la inmoralidad en todas sus formas.

\section{Actividad privada.}

La actividad privada también se ha vista contaminada en su participación en la gestión pública en su calidad de corruptores, participando en licitaciones públicas, adjudicación de obras, concursos de precios y otras modalidades de adquisiciones con el estado de forma irregular y delictiva.

La red de la inmoralidad no tiene límites ni fronteras, el enriquecimiento ilícito llega a niveles insospechables, no hay explicación valedera de apostar por este camino equivocado y de comprometer a sus familias y a sus empresas.

También las organizaciones empresariales del Perú, en sus diferentes sectores deben asumir su responsabilidad y apostar por una actividad empresarial licita, con valores y transparencia en la gestión privada y desarrollar productos y servicios de calidad para atender los mercados nacionales y globales.

La inversión nacional privada contribuye al desarrollo del país y debe asumir su liderazgo en esta materia en todos los sectores productivos y de servicios.

\section{Rol del administrador profesional en el desarrollo del país.}

En el país grandes sectores de la sociedad no conocen la participación del profesional de la Ciencia Administrativa en el desarrollo del país, por muchas razones, por ejemplo no contar con un colegio profesional que integre a todos los miembros de la orden, conocer su capacidad de gestores, su labor académica y de investigación en la formación profesional , no contar con investigaciones básicas y aplicadas de calidad, no apostar por la producción intelectual, no promover el desarrollo de artículos o papers científicos y tecnológicos en revistas científicas y tecnológicas, no difundir las líneas de competencias profesionales en el sector privado y público, dentro de una cultura de valores y deontología profesional. Este apretado análisis debe ser revertido, porque los Administradores de Empresas son los llamados a liderar las empresas para lograr su rentabilidad económica y social.

\section{Consejo nacional de ciencia, tecnología e innovación.}

Al Consejo Nacional de Ciencia, Tecnología e Innovación (CONCYTEC) no le asignan los presupuestos para promover la investigación básica o aplicada en las distintas líneas de competencia del profesional de la Ciencia Administrativa, supuestamente por que considera a la Administración como una ciencia liberal intrascendente en el desarrollo del país, compartiendo el mismo sentir con las Ciencias Económicas y Ciencias Contables, visión totalmente sesgada lejos de la realidad del mundo globalizado y competitivo, esta situación se refleja en la escasa producción intelectual, investigaciones y papers o artículos académicos asociados al desarrollo del país.

Además, no podemos estar indiferentes con nuestro capital humano más capacitado en la ciencia administrativa y que termine dedicándose a otras labores que, por falta de incentivos salariales y oportunidades de trabajo, deben contribuir con el desarrollo de nuestro país.

En consecuencia: planteo concertar un foro de discusión y de reflexión a nivel de las Facultades de Ciencias Administrativas a nivel nacional, para enriquecer mi propuesta, que solo tiene el propósito de contribuir a mejorar la calidad educativa y de la formación profesional en el país dentro de una formación de excelencia y cultura de valores. 


\section{CONCLUSIONES}

Se plantea las siguientes conclusiones:

\section{- Círculos de transparencia en la gestión}

Creación en las entidades públicas y privadas de los Círculos de Transparencia en la Gestión, para revisar y analizar los planteamientos de los colaboradores y clientes respecto a problemas, denuncias y mejoras continuas en la gestión y calidad de los productos y servicios.

\section{- Marco político:}

Consolidar la no relección de los gobernantes, parlamentarios, autoridades de gobiernos regionales y locales, así como la designación de Directorios y demás cargos del primer nivel organizacional de la administración pública para garantizar la alternancia al poder en una democracia. Presentación de los informes de gestión al finalizar su periodo con fines de evaluación

\section{- Marco legal:}

Reforzar el marco legal para combatir todo acto administrativo no ajustado a ley, incorporando en la Constitución Política del Estado y legislación de menor jerarquía legal los mecanismos legales que permitan la aplicación de medidas disciplinarías a sus infractores, respetando el debido proceso y derecho a la defensa. Modernizar la legislación laboral pública y privada, que permita precisar los deberes y derechos de los trabajadores y su responsabilidad en la gestión y administración de sus recursos. Dejar sin efecto los regímenes especiales como el CAS.

\section{- Marco económico:}

Los factores y sus indicadores macroeconómicos del país como el PBI demuestran que la economía del país se mantiene en los estándares de desarrollo 4\%, pudiéndose incrementar por la cantidad de recursos renovables y no renovables que tiene el Perú, sin embargo, el ingreso per cápita de sus habitantes está muy por debajo de cubrir la canasta familiar. La falta de transparencia en la gestión pública y en el manejo económico y la crisis política que vive el país han contribuido en gran parte a su inercia. No se ha podido encontrar en estadísticas confiables montos aproximados de que lo representa lavados de activo, enriquecimiento ilícito, dineros mal habidos en paraísos fiscales y su impacto en la economía y en la recuperación de los indicadores sociales y de la salud.

\section{- Marco social:}

Desarrollar programas de responsabilidad social en todas las entidades públicas y privadas como un compromiso de darle rostro humano a la gestión empresarial y su compromiso con las poblaciones vulnerables dentro de una política de inclusión social.

\section{- Marco educativo:}

Apostar por una educación de calidad en todos sus niveles, desarrollando la parte cognitiva y afectiva de los alumnos con una educación basada en valores e identidad nacional. Adjunto una propuesta de mejora del Sistema Educativo del Perú (Ver figura 8).

\section{- Función pública:}

Debe entenderse como una vocación de servicio a la sociedad y no como una forma de ganar una remuneración por encima del mercado laboral, despolitizando a la administración pública con una línea de carrera profesional, técnica y administrativa, que la motiva y asumas nuevos compromisos de cambio. Combatir la corrupción en todos sus frentes.

\section{- Actividad privada:}

Si existen corruptos en la gestión pública es porque hay corruptores provenientes de la actividad privada, este binomio dañino debe ser sancionado drásticamente aplicando los dispositivos legales que correspondan.

\section{- Rol del administrador profesional:}

El profesional de la Ciencia Administrativa está llamado a prestar sus servicios profesionales con Deontología Profesional, basado en valores, ética y solvencia moral. 


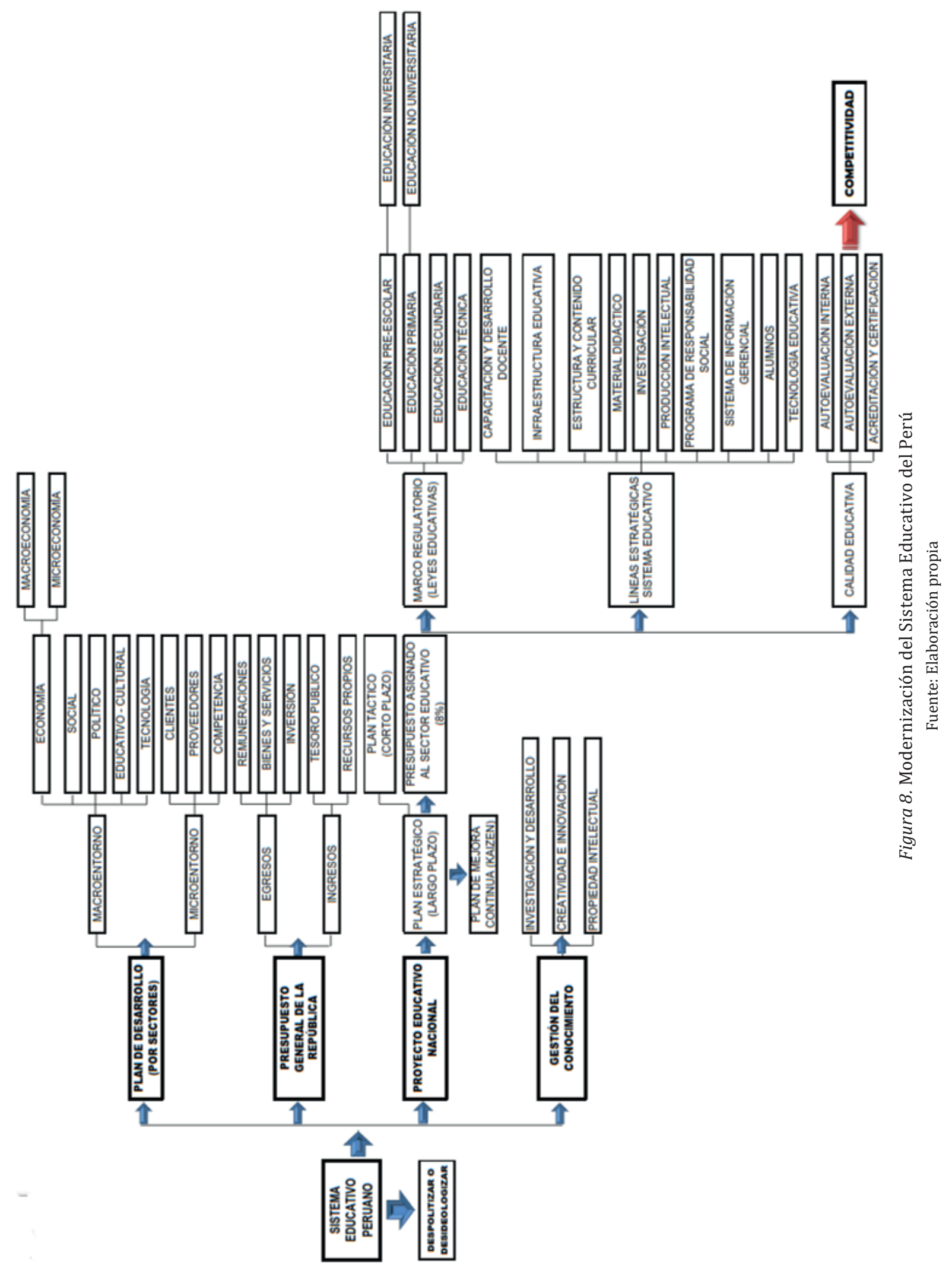




\section{REFERENCIAS BIBLIOGRÁFICAS}

Acerca del BID | IADB. (s. f.). Recuperado 23 de abril de 2019, de https://www.iadb.org/es/acercadel-bid/preparacion-evaluacion-y-aprobacionde-proyectos-en-el-bid\%2C6240.html

Actualización de Perspectivas de la Economía Mundial, Julio de 2018: Expansión menos uniforme, crecientes tensiones comerciales. (s. f.). Recuperado 23 de abril de 2019, de IMF website: https://www.imf.org/es/Publications/WEO/ Issues/2018/07/02/world-economic-outlook-update-july-2018

Comisión Económica para América Latina y el Caribe. (2019, abril 15). Nuevo número de Revista CEPAL aborda los problemas de la dependencia en recursos naturales y los retos de la innovación en la región [Text]. Recuperado 23 de abril de 2019, de https://www.cepal.org/es/comunicados/nuevo-numero-revista-cepal-aborda-problemas-la-dependencia-recursos-naturales-retos-la

Comisión Económica para América Latina y el Caribe. (s. f.). Revista CEPAL no. 127 [Text]. Recuperado 23 de abril de 2019, de https://www.cepal.org/ es/publicaciones/tipo/revista-cepal/127

Fariza, I., \& Linde, P. (2018, setiembre). El dinero público malgastado en América Latina bastaría para acabar con la pobreza extrema / Economía / EL PAÍS. Recuperado de https:// elpais.com/economia/2018/09/24/actualidad/1537762790_089270.html
FMI -- Página inicial del Fondo Monetario Internacional (FMI) en español. (s. f.). Recuperado 23 de abril de 2019, de https://www.imf.org/external/spanish/index.htm

Fondo Monetario Internacional. (2018). Perspectivas Económicas: Las Américas - Una recuperación despareja; octubre de 2018. Recuperado de

INEI: Evolución de la Pobreza Monetaria 2007-2016. (2017, mayo). Recuperado de https://www.inei. gob.pe/media/MenuRecursivo/publicaciones_ digitales/Est/Lib1425/

Inter-American Development Bank - IADB.org. (s. f.). Recuperado 23 de abril de 2019, de https:// www.iadb.org/es

Jaramillo, C. F., \& Silva-Jauregui, C. (2011). Perú en el umbral de una nueva era: lecciones y desafíos para consolidar el crecimiento económico y un desarrollo más incluyente. Lima: Banco Mundial.

Pobreza en el Perú disminuyó 1.2 puntos en 2018, según el INEI | Publimetro Peru. (2019, abril 10). Recuperado 23 de abril de 2019, de Redacción Publimetro website: https://publimetro.pe/actualidad/noticia-pobreza-peru-disminuyo-1-2-puntos-2018-inei-nndc-106175

Proyectos del BID | IADB. (2019). Recuperado 23 de abril de 2019, de BID Mejorando vidas website: https://www.iadb.org/es/proyectos 
